\title{
Diel and seasonal patterns in acoustic presence and foraging behaviour of free-ranging harbour porpoises
}

\author{
Tobias Schaffeld ${ }^{1,2,3, *}$, Stefan Bräger ${ }^{1,4}$, Anja Gallus $^{1}{ }^{,}$Michael Dähne ${ }^{1,3}$, \\ Kathrin Krügel $^{1}$, Anne Herrmann ${ }^{1}$, Martin Jabbusch ${ }^{1}$, Thomas Ruf ${ }^{5}$, \\ Ursula K. Verfuß ${ }^{1,6}$, Harald Benke ${ }^{1}$, Jens C. Koblitz ${ }^{1,7}$ \\ ${ }^{1}$ German Oceanographic Museum, Katharinenberg, 18439 Stralsund, Germany \\ ${ }^{2}$ University of Natural Resources and Life Sciences, 1180 Vienna, Austria \\ ${ }^{3}$ Institute for Terrestrial and Aquatic Wildlife Research, University of Veterinary Medicine Hannover, Foundation, \\ 25761 Büsum, Germany \\ ${ }^{4}$ International Seabed Authority, Kingston, Jamaica \\ ${ }^{5}$ Research Institute of Wildlife Ecology, University of Veterinary Medicine Vienna, 1160 Vienna, Austria \\ ${ }^{6}$ SMRU Consulting, Scottish Oceans Institute, St. Andrews KY16 9SR, UK \\ ${ }^{7}$ BioAcoustics Network, 18439 Stralsund, Germany
}

\begin{abstract}
A temporal and geographical analysis of echolocation activity can give insights into the behaviour of free-ranging harbour porpoises Phocoena phocoena. Seasonal and diel patterns in the presence and foraging activity of harbour porpoises were investigated based on a year-long passive acoustic monitoring data set recorded at 5 sites in the western Baltic Sea. Diel patterns in detection rates were found at 4 sites. A year-round rhythm in presence, however, was found at only 1 station, whereas the other 3 stations showed diel rhythms for 2 to 3 seasons. Three of the sites showed diel patterns in foraging sequences on a seasonal level, but no station showed such patterns for the complete year of investigation. Both diurnal and nocturnal patterns in harbour porpoise detections were observed, indicating that diel rhythmic behaviour is more complex than previously reported. In contrast, foraging behaviour showed only nocturnal rhythms. Owing to the limitations in passive acoustic monitoring, all categorized foraging sequences are a minimum estimate. Therefore, classified foraging sequences are most likely pelagic foraging, while bottom grubbing could have been missed. Differences in the occurrence of foraging sequences between station, season and time of day lead to the assumption that the long-term echolocation diel patterns of porpoises strongly depend on the temporal changes in food availability and composition within a certain habitat. Echolocation behaviour of foraging porpoises is strongly influenced by seasonally available prey resources, which require adaptive foraging strategies. Therefore, owing to seasonal variations, analyses of diel patterns need to be conducted over sufficiently long time periods and large geographic scales to allow generalized interpretation of the findings. Consequently, no general conclusion regarding diel rhythms in harbour porpoise echolocation was found. We hypothesize that porpoises in the study area alternate between foraging on benthic prey in shallow waters at daytime and in the pelagic in deeper waters at night.
\end{abstract}

KEY WORDS: Cosinor analysis $\cdot$ Diel rhythms $\cdot$ Predation $\cdot$ Phocoena phocoena

\section{INTRODUCTION}

Like all toothed whales (Odontoceti), harbour porpoises have developed an active acoustic sense, echolocation, to acquire information about their envi-

\footnotetext{
${ }^{*}$ Corresponding author: tobias.schaffeld@tiho-hannover.de
}

ronment. To do so they emit series of pulsed, highfrequency clicks to receive information on their surroundings, including possible prey items, from the returning echo ( $\mathrm{Au}$ 1993). Harbour porpoises are known to echolocate almost constantly, emitting

() The authors 2016. Open Access under Creative Commons by Attribution Licence. Use, distribution and reproduction are unrestricted. Authors and original publication must be credited. 
echolocation clicks on average every $12.3 \mathrm{~s}$ (Akamatsu et al. 2007). Maximum periods with no clicks, or clicks with amplitudes below recording threshold, ranging from 99 to $1300 \mathrm{~s}$ were found for 3 free-ranging porpoises equipped with acoustic data loggers (Linnenschmidt et al. 2013). Although diel variations and rare periods of silence occurred, Linnenschmidt et al. (2013) concluded that harbour porpoises echolocate almost continuously. Verfuß et al. (2009) showed that harbour porpoises use echolocation for orientation and foraging during daylight in relatively clear water conditions, independent of their ability to use eyesight or not (e.g. when blindfolded). Porpoises thus appear to use their echolocation independently of light conditions. They emit specific click patterns for orientation and prey capture (Verfuß et al. 2005, DeRuiter et al. 2009, Verfuß et al. 2009) and also for intraspecific communication (reviewed in Koschinski et al. 2008, Clausen et al. 2011). Click patterns thus allow the discrimination of different behavioural categories such as communication (Clausen et al. 2011), foraging (Koschinski et al. 2008, DeRuiter et al. 2009, Verfuß et al. 2009, Linnenschmidt et al. 2013), or the use of local objects to lock on and approach during the navigation from one point to another (Verfuß et al. 2005). According to Verfuß et al. (2009) foraging sequences can be separated into different phases by changes in echolocation behaviour, leading to altered inter-click intervals (ICI). The pattern in ICI during the search phase seems to be driven by a range locking to objects until a potential target can be detected. In captivity, the initial part of the approach phase is characterised by relatively stable ICI of around $50 \mathrm{~ms}$ (Verfuß et al. 2005). The terminal part of the approach phase is marked by a sudden and rapid shortening of ICI to levels of below $10 \mathrm{~ms}$ (DeRuiter et al. 2009, Verfuß et al. 2009). The ICI can reach a minimum of around $1.5 \mathrm{~ms}$ and remains constant at a distance of less than $1 \mathrm{~m}$ to the prey (Verfuß et al. 2009). In accordance with patterns in echolocation sequences of insectivorous bats during the final stage of a foraging attempt, click sequences with a short and stable ICI of below $10 \mathrm{~ms}$ are called 'buzzes' (Miller et al. 1995, DeRuiter et al. 2009, Verfuß et al. 2009, Madsen \& Surlykke 2013). A rapid increase in ICI marks the end of the terminal part of the approach phase. At least 2 genetically and morphologically distinct populations of harbour porpoise Phocoena phocoena have been identified in the waters of the Baltic Sea (Wiemann et al. 2010, Galatius et al. 2012). One population inhabiting the southern part of the Kattegat, the Belt Seas, the Sound and the western Baltic has an abundance of 40475 (CI 25614 to 65 041) individuals (Viquerat et al. 2014). The other population, inhabiting in the Baltic Proper, has been classified by the International Union for Conservation of Nature (IUCN) as Critically Endangered (Hammond et al. 2008). P. phocoena have high energy demands due to their small body size and thermoregulatory costs caused by the temperate waters they inhabit (Koopman 1998). Their small size does not allow for the storage of energy reserves, thus leading to a high dependence on the year-round availability of food resources (Santos et al. 2004). Therefore, seasonal shifts in porpoise distribution (Verfuß et al. 2007, Benke et al. 2014) may be explained best by changes in prey densities (Sveegaard et al. 2012) and availability. For example, spring migrations of harbour porpoises into the Baltic Sea are known to track migrating herring to the spawning grounds (Koschinski 2002 and citations therein), and harbour porpoise occurrence is positively correlated with herring densities (Sveegaard et al. 2012). Diet regularly consists of the most abundant prey items (Christensen \& Richardson 2008), which is typical for a generalist and opportunistic feeder. According to stomach content analysis, the most abundant fish species in the local harbour porpoise diet are herring Clupea harengus, cod Gadus morhua and gobies (Gobiidae) (Lick 1991, Sveegaard et al. 2012). In the period between April and October, cod is the most important prey item, whereas in the period from November to March, cod and herring are of equal importance for harbour porpoises (Sveegaard et al 2012). These species vary in size, caloric content, life cycle, water depth preference and migratory potential, and the availability of preferred fish species varies throughout the year (Sveegaard et al. 2012). A daily consumption of 3.5 to $5.5 \mathrm{~kg}$ has been reported for porpoises in Danish waters (Lockyer 2007). Furthermore, there appear to be differences in the diet composition between harbour porpoises of different ages. For instance, gobies and shrimps are more commonly preyed upon by sub-adults (Lick 1991, Santos et al. 2004). These dietary changes could possibly be a result of different foraging strategies, depending on available prey items throughout the year, and depending on life stage to maximise energy intake while minimising energy expenditure during foraging.

Just as Mysticetes (baleen whales) show rhythms in their vocal behaviour (e.g. Risch et al. 2013), diel and seasonal changes in acoustic (and foraging) behaviour are known also for various odontocete (toothed whale) species. Pacific white-sided dolphins Lagenorhynchus obliquidens change between 2 different click bout patterns from day to night, which 
is assumed to be related to prey species (Soldevilla et al. 2010a). Similar rhythmic changes in the quantity or quality of vocalisations on a daily or seasonal basis have been recorded for short-beaked common dolphins Delphinus delphis (Goold 2000), Risso's dolphins Grampus griseus (Soldevilla et al. 2010b), finless porpoises Neophocaena phocaenoides (Akamatsu et al. 2010, Wang et al. 2014, 2015a, Dong et al. 2015), Heaviside's dolphins Cephalorhynchus heavisidii (Leeney et al. 2011), Ganges river dolphins Platanista gangetica gangetica (Sasaki-Yamamoto et al. 2013), bottlenose dolphins Tursiops truncatus (Dede et al. 2014) and Amazon river dolphins Inia geoffrensis (Yamamoto et al. 2015), as well as assemblages of several odontocete species possibly feeding together (Au et al. 2013, 2014, Hodge et al. 2013, Lin et al. 2015). Nocturnal patterns in presence and foraging activity have been also found for Indo-Pacific humpback dolphins Sousa chinensis (Wang et al. 2015b). Higher nocturnal presence often associated with an increased foraging activity has been shown previously also for free-ranging harbour porpoises in the Baltic Sea by analysing diel patterns in their vocalisations (Carlström 2005, Todd et al. 2009, Dähne et al. 2013, Linnenschmidt et al. 2013, Mikkelsen et al. 2013, Brandt et al. 2014).

For example, distinct daily rhythms in the echolocation behaviour of harbour porpoises in the Baltic Sea, with increased echolocation encounter rates during the night and decreased ICI, could be identified by Carlström (2005) and Todd et al. (2009). This striking nocturnal rhythm was also found at a reestablished stony reef in the Kattegat (Denmark), whereas an opposite diurnal rhythm with higher activity during the day was found for a reference position approximately $20 \mathrm{~km}$ away (Mikkelsen et al. 2013). Differential findings for diel rhythms were also shown by Linnenschmidt et al. (2013), who found a clear nocturnal rhythm in echolocation rates for a nearshore individual, whereas no rhythm for an individual in open waters could be found. In contrast, a more pronounced daily rhythm at deeper positions was found by Brandt et al. (2014).

General conclusions, however, about unaffected diel rhythms of harbour porpoises in their natural habitat are rare. The presence of large artificial structures (Todd et al. 2009, Mikkelsen et al. 2013, Brandt et al. 2014) could alter behavioural patterns compared to natural habitats. Likewise, the catching and tagging of the animals might have an effect on the natural behaviour of an animal, which should be more relevant in short-term studies (Linnenschmidt et al. 2013).
For the results presented here, a non-invasive approach to analysing echolocation in harbour porpoises in their natural habitat was chosen, over a large geographical scale and over a period of 12 mo. Data were gathered with stationary passive acoustic monitoring (PAM) devices to allow for the analysis of acoustic detection rates over large geographic areas in high temporal resolution.

The frequency of foraging events within acoustic detections is expected to indicate the distribution of prey. Furthermore, foraging success is likely to affect individual fitness and indirectly also population health. This study explores acoustic detection rates and therein the distribution of foraging click trains to elucidate how free-ranging porpoises use their habitat with relation to their foraging behaviour.

\section{MATERIALS AND METHODS}

\section{Study location}

The data were gathered at 5 stations around the island of Fehmarn and the Kadet Trench in the German part of the western Baltic Sea during a 12 mo period from April 2006 to March 2007 (Fig. 1). The stations differed in water depth, ranging from 8 to $28 \mathrm{~m}$, with 2 stations in less than $10 \mathrm{~m}$ (Stns 1 and 5) and 3 stations in more than $20 \mathrm{~m}$ (Stns 2, 3 and 4; Table 1). A total of 3 stations were relatively close to the coast (Stns 1, 2 and 5), whereas 2 stations were farther offshore (Stns 3 and 4). Stns 2, 3 and 4 were located close to main shipping routes with potentially high impacts by ship traffic.

All timing-porpoise detectors (T-PODs; Chelonia) were deployed in the water column at a depth of 5 to $7 \mathrm{~m}$ below the surface. Consequently, the distance from the T-POD to the surface was the same for all stations, while the distance to the bottom was dependent on water depth and differed between stations.

\section{PAM}

Static acoustic monitoring of harbour porpoises has been carried out in the German Baltic Sea since 2002 using autonomous echolocation click loggers like TPODs. These self-contained devices provide information on harbour porpoise presence and acoustic behaviour by logging echolocation-like clicks with the time of their occurrence and duration. The clicks are recorded by a hydrophone at the top of the 


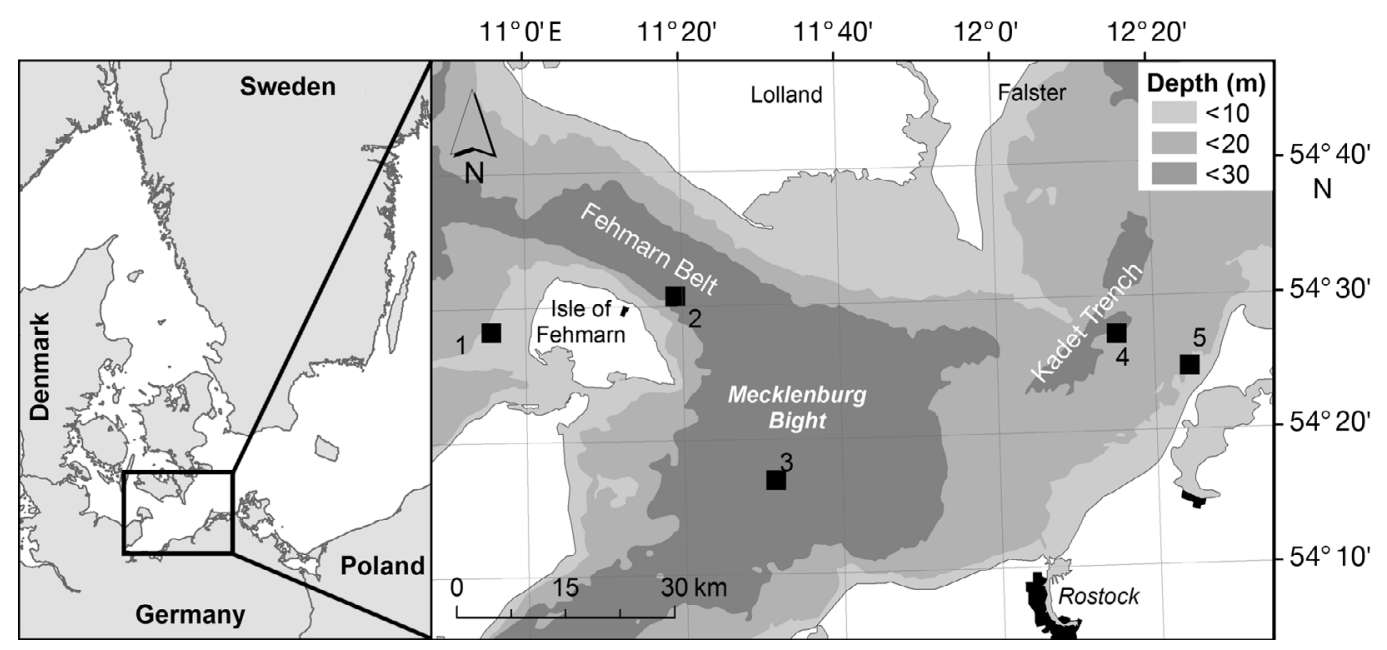

Fig. 1. Overview (left ) and detailed map (right) of the study area in the western part of the German Baltic Sea, with all 5 measuring stations (black squares) holding 1 timing-porpoise detector (T-POD) each for monitoring harbour porpoises acoustically. Water depth is shown by different coloration

T-POD and afterwards amplified and filtered by 2 band-pass filters. The so-called target filter is fitted to $130 \mathrm{kHz}$, the peak frequency in harbour porpoise clicks. The reference filter is set at $90 \mathrm{kHz}$, representing a frequency with no or little energy in harbour porpoise clicks. The sensitivity of a T-POD is also adjusted, corresponding to individual device performance to enable comparable results for all $\mathrm{T}$ PODs. The detection threshold for all T-PODs was adjusted to $127 \mathrm{~dB}$ re $1 \mu \mathrm{Pa}$ peak-peak. A recorded signal is classified as a porpoise signal by the T-POD if the ratio between the energy of the signal output and the reference filter exceeds a defined value. Additionally, the signal has to exceed a set detection threshold in duration and sound pressure level (Kyhn et al. 2008, Verfuß et al. 2008, 2010, 2013, Gallus et al. 2012). The maximum number was set to 240 clicks recorded in each scan ( 9.17 s) to save battery power and memory storage. The T-POD settings were similar for all devices. For more details on the T-POD settings and their moorings, see Verfuß et al. (2008) and Gallus et al. (2012).

In general, the PAM approach cannot discriminate between the absence of animals and a change (decrease of clicks) in echolocation behaviour, and only possible changes in the echolocation behaviour can be evaluated but not changes in the behaviour itself. Moreover, no information on the number of individuals recorded at a PAM station is available, and detection ranges can vary. The high temporal and geographical resolution enables a detailed analysis of possible rhythms in all porpoise clicks, which have been recorded over a large geographic scale.

\section{Signal processing and detection of harbour porpoise presence}

The software T-POD.exe Version 7.41 was used to download the gathered data. Afterwards, data were processed using the train detection algorithm Version 3.0. All click trains that were classified by the software into categories from 'cet high' to 'very doubtful' were double-checked visually to eliminate false positive sequences. The progression of ICI and the duration of individual clicks were used to verify clicks as being produced by a harbour porpoise (see Koschinski et al. 2008 for examples of detected harbour porpoises by the use of T-PODs). Sequences containing a minimum of 5 clicks have been classified as a porpoise click sequence (Verfuß et al. 2007, Gallus et al. 2012). Any 10 min period that contained at least 1 visually confirmed porpoise click sequence was classified as a porpoise-positive $10 \mathrm{~min}$ period (pp10min), resulting in a binary coded data set with 0 for absence and 1 for presence. Owing to a limited detection range and angle of the PAM approach, it is possible that harbour porpoises were present without being detected or that not all foraging sequences were detected. Consequently, no conclusion is possible on absence data in terms of registrations or foraging behaviour. No information about the proportion of false negatives is available. Therefore, only minimum estimates of porpoise detections can be assessed. Porpoise detection rates were computed as the proportion of pp10min intervals for the whole period of investigation (Table 1) and per hour. 
Table 1. Recorded data set for the entire time of investigation, separated for each station and its totals. pp10min: porpoise-positive 10 min period; f10min: foraging-positive $10 \mathrm{~min}$ period

\begin{tabular}{|lcccccc|}
\hline Parameter & Stn 1 & Stn 2 & Stn 3 & Stn 4 & Stn 5 & Mean \\
\hline Water depth (m) & 8 & 28 & 23 & 20 & 10 & 17.8 \\
$\begin{array}{l}\text { Missing obs. (10 min } \\
\text { periods; \% yr }{ }^{-1} \text { ) }\end{array}$ & 0.4 & 9.9 & 1.6 & 26.9 & 13.0 & 10.36 \\
$\begin{array}{l}\text { No. of pp10min } \\
\text { pp10min (\% per complete }\end{array}$ & 1922 & 4014 & 2268 & 895 & 737 & 1967.2 \\
$\quad$ obs. period) & 4.7 & 8.5 & 4.4 & 2.3 & 1.6 & 4.1 \\
$\begin{array}{l}\text { No. of fp10min } \\
\text { fp10min (\% per pp10min) }\end{array}$ & 2.2 & 9.0 & 5.3 & 5.4 & 4.5 & 6.2 \\
$\begin{array}{l}\text { No. of blocks with buzz } \\
\text { content }\end{array}$ & 74 & 502 & 200 & 80 & 45 & 901 \\
pp10min with buzz & 3.85 & 12.5 & 8.82 & 8.94 & 6.11 & 9.16 \\
$\quad$ content (\%) & & & & & & \\
\hline
\end{tabular}

\section{Classification of foraging sequences}

For the evaluation of potential foraging sequences, all click trains classified to be of porpoise origin were taken into account. In accordance with previous studies, we used the detection of click sequences with a minimum ICI of below $10 \mathrm{~ms}$ as a first indicator for foraging activity (Carlström 2005, Todd et al. 2009, Verfuß et al. 2009, Linnenschmidt et al. 2013, Nuuttila et al. 2013). Foraging sequences of harbour porpoises can show extreme variations in ICI before a sudden decrease to below 10 ms occurs (Fig. 2). As a first approach, only sequences that (1) showed a sudden decrease in ICI, (2) consisted of at least 5 clicks below an ICI of $10 \mathrm{~ms}$ and (3) also contained clicks at an ICI level between 40 and $70 \mathrm{~ms}$ before the decrease (representing the initial part of the approach phase) were categorized as foraging sequences. In total, 901 pp10min periods with buzz content were analysed, resulting in only 137 periods meeting all of these criteria.

Therefore, a generalized additive mixed model (GAMM; Lin \& Zhang 1999, Wood 2006, 2011) with 10 random foraging sequences was conducted as a training set to find the best criterion for the classification of foraging sequences. The model was evaluated using the procedure described in Zuur et al. (2010). Echoes and overly long ICI (>100 ms) were removed prior to modelling using a custom-written $\mathrm{R}$ script based on ratios of successive ICI. Sounds having an ICI of below $15 \mathrm{~ms}$ with a ratio of $1 / 4$ of the previous ICI were deleted. The 10 sequences were aligned at the first value below $10 \mathrm{~ms}$, using and comparing a moving average of 3 ICIs, using $20 \mathrm{~s}$ before and $5 \mathrm{~s}$ after alignment as the length of each sequence. The GAMM was constructed using the ICI as dependent, time as independent and sequence number as
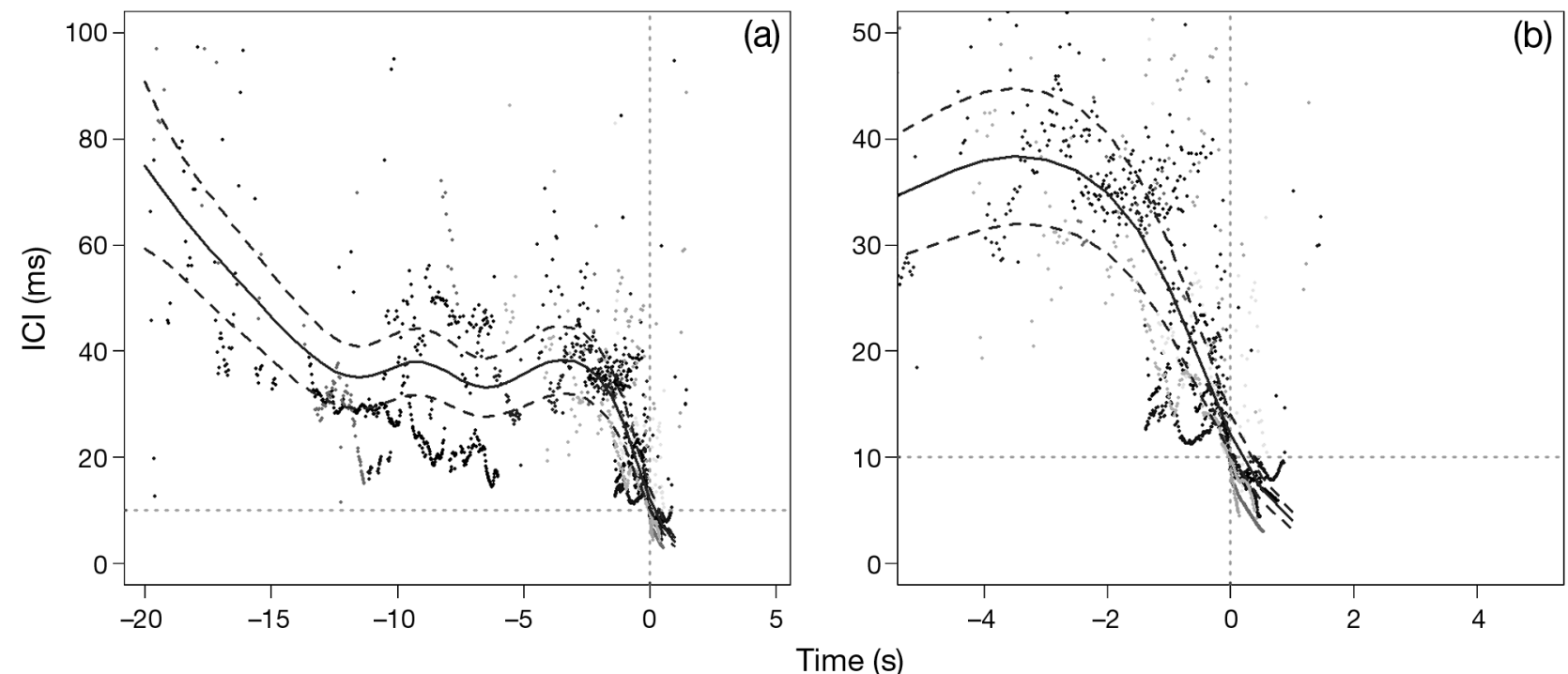

Fig. 2. Ten foraging sequences of harbour porpoises recorded in the field with T-PODs and overlayed generalized additive mixed model (GAMM)-smoother. Individual sequences are separated by grey scales. Black lines show the prediction of the GAMM with its $95 \%$ CI as dashed lines. Grey dashed lines show the point of alignment for the sequences. (a) Complete sequence from $20 \mathrm{~s}$ prior to alignment until $5 \mathrm{~s}$ after and (b) enlargement of the final sequence prior to the potential prey catch. 
random term (factor), using the library mgcv (Wood 2011) in R with a Poisson distribution corrected for overdispersion with a log-link. Akaike's information criterion (AIC) was used for model comparisons. For the 10 analysed foraging sequences, ICI was suspected to be significantly influenced by time, which could be proved by the GAMM (estimated $\mathrm{df}=8.754$, $F=347.5, \mathrm{p}<0.001$, intercept $=3.03, t=37.97, \mathrm{n}=$ 1979 , adjusted $\mathrm{R}^{2}=58 \%$; AIC was reduced in models using no random term) (Fig. 2). The final segment of the buzz is missing in most field recordings on $\mathrm{T}$ PODs, most likely due to a limit of 240 clicks recorded in each scan of $\sim 9.17 \mathrm{~s}$ duration: when clicks are emitted by porpoises at a repetition frequency of around 500 clicks per second or higher (see Verfuß et al. 2009), the clicks recorded sum up to the set scan limit in $\sim 0.5 \mathrm{~s}$. The model shows large $95 \%$ CI before the ICI drops to below $\sim 30 \mathrm{~ms}$. The smoothing spline confirms the assumption that the sudden decrease in ICI to below $10 \mathrm{~ms}$ is the most stereotypical part of foraging sequences recorded by T-PODs, by reason that CI around $10 \mathrm{~ms}$ are becoming narrow.

The presented classification of foraging sequences is assumed to be a more conservative indicator for foraging events than using ICIs below $10 \mathrm{~ms}$. In contrast to previous studies, we used the sudden decrease in ICI, indicated by a drop to $2 / 3$ of its initial value within $2 \mathrm{~s}$, preceding the buzz as described in Verfuß et al. (2009), as the criterion for foraging sequences. Click sequences with a relatively constant ICI of 1.5 to $2.5 \mathrm{~ms}$ that did not show a sudden decrease in ICI were therefore not categorized as foraging activity.

Foraging-positive $10 \mathrm{~min}$ periods (fp10min) were defined as pp10min containing a minimum of at least 5 clicks with an ICI below $10 \mathrm{~ms}$ and a sudden decrease in ICI within $2 \mathrm{~s}$ to below $10 \mathrm{~ms}$. A probability of harbour porpoise foraging was generated as the proportion of fp10min intervals per pp10min for the whole period of investigation (Table 1), and for the proportion of fp10min intervals per pp10 $\mathrm{min}^{-1}$, corrected for differences in length of day and night .

\section{Temporal analysis}

Diel rhythms are defined as changes in behaviour in relation to day and night cycles. Day was defined as the period between sunrise and sunset, and night accordingly as the period between sunset and sunrise. Diurnal patterns are defined as any behaviour that occurs during daytime, whereas nocturnal describes any activity during night.
The local times of sunrise and sunset were downloaded for the geographic position of each station with the software program R (R Core Team 2013) based on information from an online database (http:// lexikon.astronomie.info/zeitgleichung/; retrieved 16 June 2013). Data were separated into seasonal subsets for spring (April to June), summer (July to September), autumn (October to December) and winter (January to March).

\section{Statistical analysis}

\section{Lomb-Scargle periodograms}

Specific statistical processes are required for the analysis of rhythms in biological data, especially for the detection of weak rhythmic components in noisy data. Possible rhythms in pp10min and fp10min periods were determined by the Lomb-Scargle periodogram (LSP; Lomb 1976, Scargle 1982, Ruf 1999). The LSP is commonly used in astrophysical sciences and originates from but is not identical to, the classical Fourier spectrum analysis (Lomb 1976, Scargle 1982, Ruf 1999); it also proved to be effective in detecting rhythmicity in biological data (e.g. LópezDuarte \& Tankersley 2007, Campos et al. 2008, López-Duarte et al. 2011, Frohlich et al. 2012, Mat et al. 2012). This algorithm was chosen because of its ability to handle unequally sampled data, such as incomplete time series, or zero-inflated data like time series with a huge amount of zeros accounting for probable absence of animals. The data set in this study was binary coded, indicating presence or absence of harbour porpoises. To obtain a continuous numerical response, variable hourly means of the binary coded original data were calculated for each station prior to computing the LSP. Additionally, these averaged values serve as a low-pass filter for high-frequency noise but keep low frequencies like the analysed periods from 12 to $36 \mathrm{~h}$. The highest peak in normalized power (PN) and the corresponding period of the LSP of presence and foraging activity was determined for each station. Periods scanned ranged from 12 to $36 \mathrm{~h}$ with an oversampling factor (cf. Ruf 1999) of 5, which corresponded to a resolution $<0.04 \mathrm{~h}$. PN values indicate the spectral power of rhythmic components relative to the total variance in the data set as a function of angular frequency for all tested periods. Their statistical significance was determined by peak values in the periodogram exceeding the $\alpha=0.05$ level (Press et al. 1994, Ruf 1999, López-Duarte \& Tankersley 
2007 Campos et al. 2008, López-Duarte et al. 2011). A significant $\mathrm{PN}$ peak indicates that a given rhythm is better described by a sine wave than by a straight line across the mean values. All LSP values were computed using the R package lomb (Ruf 2013, version 1.0).

\section{Cosinor analysis}

On a seasonal basis, data were further analysed by a cosinor analysis (which can be carried out with data obtained for a single period of a rhythm) for rhythms in detections and foraging. For this analysis, a sinusoidal function with a period of 24 derived from LSP computation was fitted to a time series of data points to estimate the quality of the fit, the amplitude and the phase angle of the peak. For this purpose, the function $y=m+A \times \cos (t-\phi)$ was fitted, i.e. a cosine fitted to the $y$-values determined at time $t$ with an amplitude $A$ around a mean $m$, that peaks at an acrophase $\phi$ (Batschelet 1981). The significance of rhythms was computed by an ANOVA from the ratios of variances around the overall mean to residual variances around cosine curves. This cosinor analysis was applied to hourly means calculated for the entire data set for each station, as well as for each seasonal subset. Visual inspection of all model residuals via histograms and quantilequantile plots provided no evidence for a relevant deviation from normality.

\section{RESULTS}

In the 12 mo period, $10.4 \%$ of observation hours were missing (Fig. 3) due to technical failure or adverse weather conditions. A total of 235582 monitored $10 \mathrm{~min}$ periods over all 5 stations resulted in 9836 periods $(4.2 \%)$ with porpoise detections (pp10min). In 6.2\% ( $\mathrm{n}=607)$ of all pp10min, foraging behaviour was ascertained (Table 1); this constitutes $67.4 \%$ of all analysed $10 \mathrm{~min}$ periods with buzz content $(\mathrm{n}=901)$.

\section{Temporal patterns in harbour porpoise detections}

Harbour porpoise presence and foraging activity was detected at all stations during night and day with variations in the distribution between stations and seasons (Figs. $3 \& 4$ ). Harbour porpoise presence was highest at Stn $2(\mathrm{n}=4014 ; 8.5 \%)$, followed by Stns 3 ( $\mathrm{n}=2268 ; 4.4 \%$ ) and $1(\mathrm{n}=1922 ; 3.7 \%$ ) (Fig. 3, Table 1). At Stns 1 and 2, harbour porpoises were detected consistently throughout the year, whereas in winter and early spring, almost no harbour porpoises were detected at Stns 3, 4 and 5.

Relative foraging activity was highest at Stn 2 (n = 363; $9 \%)$ followed by Stn $4(\mathrm{n}=48 ; 5.4 \%)$ and Stn 3 ( $\mathrm{n}=121 ; 5.3 \%$; Table 1). Especially in late spring and winter, foraging sequences at Stn 2 were mainly detected throughout the night with a sharp demarcation at sunrise (Fig. 3). Relative foraging activity at

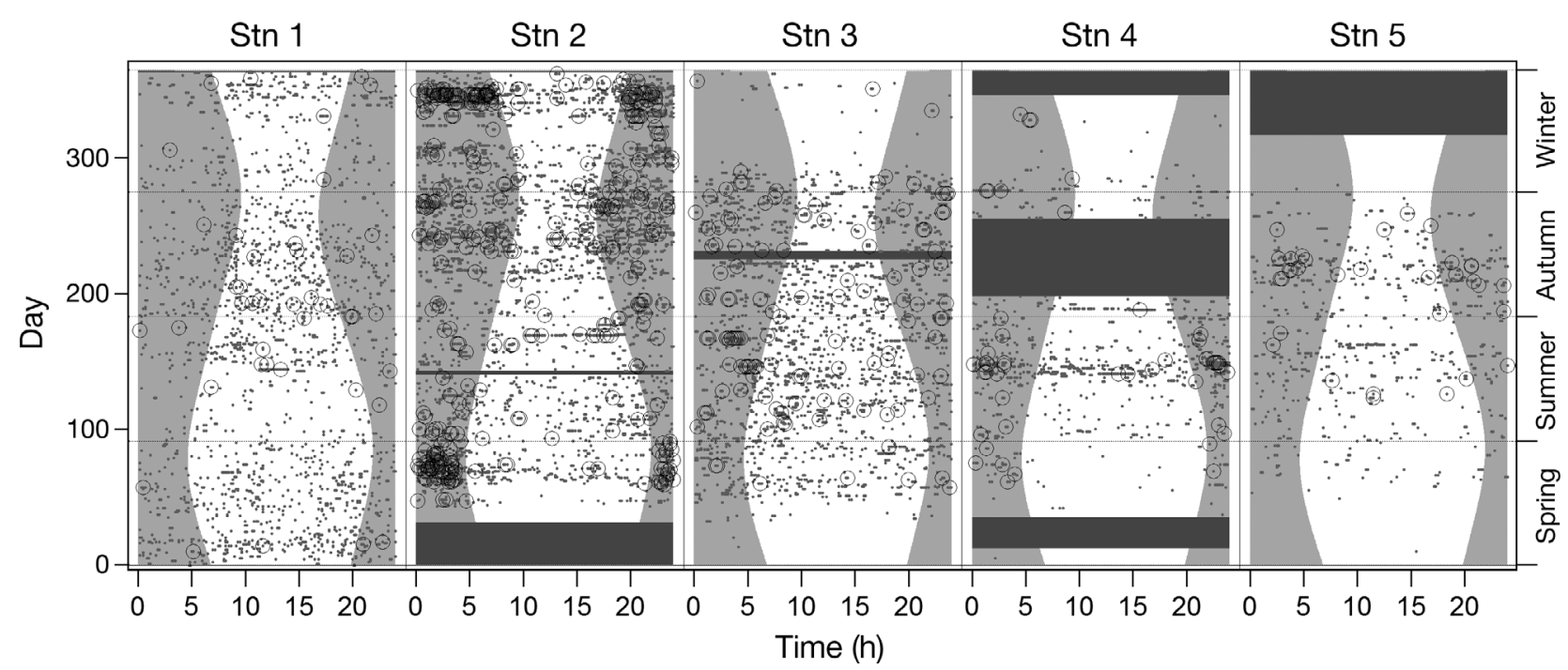

Fig. 3. Seasonal and diel distribution of harbour porpoise detections (10 min periods; black dots) for all 5 stations with superimposed foraging-positive $10 \mathrm{~min}$ periods (fp10min, circles). The represented period starts on 1 April 2006 and ends on 31 March 2007. Dotted lines separate data into seasons. Grey areas indicate night, and white areas day. The local time of sunrise and sunset was calculated for each station. The bars in dark grey indicate data gaps 
Stn $1(2.2 \%)$ was lower compared to Stn $2(9 \%)$, although the distance between these stations was relatively short (25.8 km; Fig. 1). However, relatively more foraging sequences were recorded during the day at Stn 1 . Stn 3 showed a more or less equal distribution of harbour porpoise detections throughout the year and the day, while foraging sequences tended to be more aggregated during the night. The number of foraging sequences was very low at Stn 4 but was higher during the night throughout the year. At Stn 5, most foraging sequences were recorded in late summer and autumn, while no foraging sequences were found in winter and spring. Fig. 4 allows for a comparison of harbour porpoise presence and foraging activity between stations and seasons on a diel level.

\section{Analysis of diel patterns throughout the year}

Data analysis with the LSP revealed a significant pattern with a period of about $24 \mathrm{~h}$ in harbour porpoise detections for Stns 1, 2, 3 and 4 ( $\mathrm{p}<0.05)$ (Fig. 5). Associated spectral powers (PN values) were highest at Stn 2 (PN $=120)$ followed by $\operatorname{Stn} 1(\mathrm{PN}=50)$, indicating pronounced diel rhythms. Diel rhythms could be determined also for Stns 3 and 4, but PN values were lower. Foraging sequences were also analysed for rhythms within the data (Fig. 5). A diel rhythm occurred at Stns $2(\mathrm{PN}=40)$ and $4(\mathrm{PN}=11)$.

Owing to the fact that the LSP analysis detected rhythms with a length of $24 \mathrm{~h}$ in the data, the period for the cosi-

Fig. 5. Lomb-Scargle periodograms to indicate rhythmic processes in (a) presence and (b) foraging behaviour (right column) for Stns 1 (top) to 5 (bottom). Periods tested ranged from 12 to $36 \mathrm{~h}$. Dashed lines indicate significance level at $\alpha=0.05$, i.e. peaks exceeding these lines are considered to originate from non-random rhythmic processes. PN: normalized power for each period tested

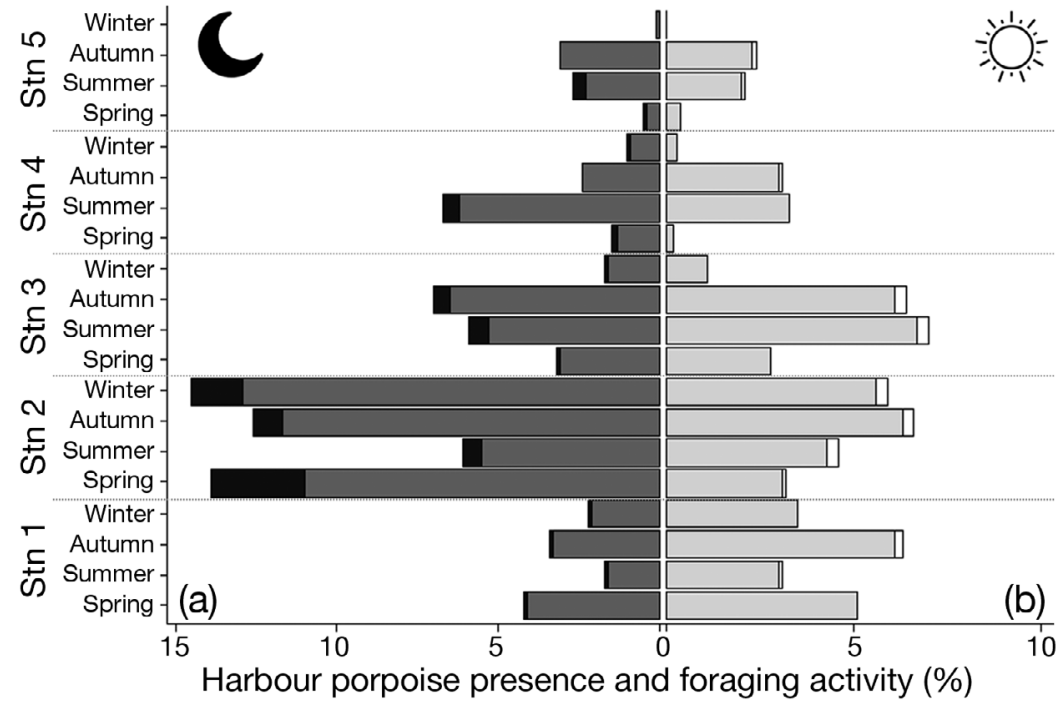

Fig. 4. Proportion of foraging activity based on harbour porpoise presence separated into (a) day and (b) night. The proportion of presence is shown by grey (night) and light grey (day) bars, whereas the foraging activity is represented by black (night) and white (day) bars. Seasonal and diel distribution of harbour porpoise presence are separated by stations and seasons. The presence is calculated as the percentage of all observed time, corrected for length of day and night

(a) Presence
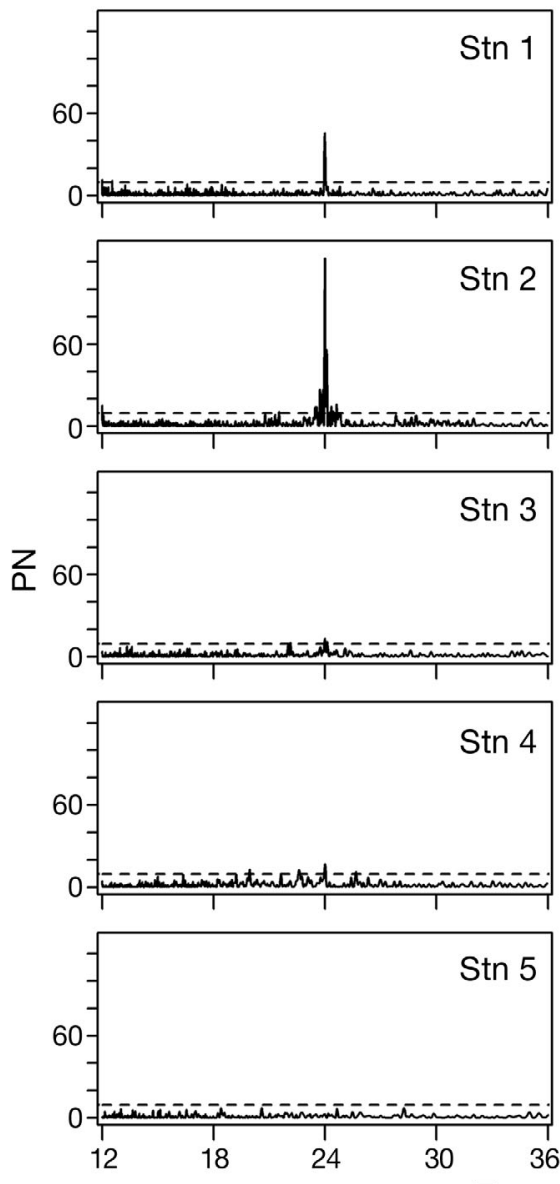

(b) Foraging
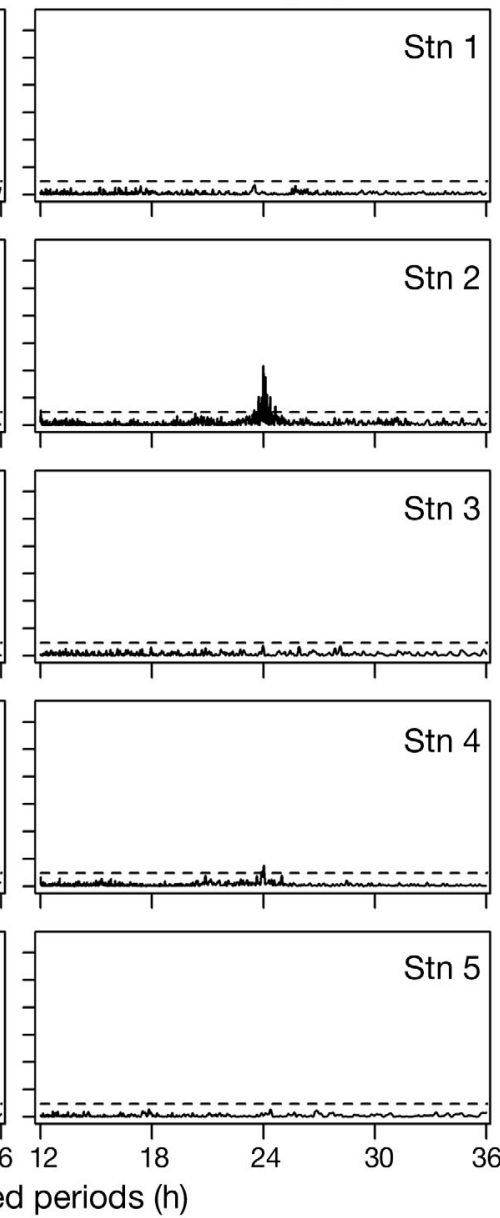
nor analysis was set to $24 \mathrm{~h}$. The analysis revealed a significant diurnal rhythm with a peak at day for harbour porpoise detections for summer, autumn and winter ( $p<0.01$ in all cases) at Stn 1 (Fig. 6). In spring, only tendencies for a diurnal rhythms could be shown $(p=0.08)$. A seasonally constant nocturnal rhythm in presence was found for Stn 2 ( $p<0.001$ in all cases). Nocturnal patterns were found in spring ( $p$ $=0.001)$ and autumn $(p<0.001)$ at Stn 3. A diurnal pattern was found in summer $(p=0.001)$. Nocturnal patterns were found at Stn 4 in spring and summer ( $p$ $<0.001)$. At Stn 5, a nocturnal pattern in harbour porpoise presence was detected for winter $(p=0.044)$ and a diurnal pattern for summer $(\mathrm{p}=0.018)$.

No evidence for diel rhythms in foraging behaviour was found for Stn 1 (Fig. 7). A significantly higher nocturnal foraging activity was ascertained at Stn 2 for spring $(p<0.001)$, autumn $(p<0.05)$ and winter $(p=0.004)$. Tendencies for a nocturnal pattern could be shown for summer also $(p=0.072)$. The dotted line in spring represents the cosine fit, which did not seem sinus-shaped. Therefore, the data were fitted alternatively by a baseline-cosine fit (black line) (Ruf 1996). At Stn 3, a diurnal pattern in foraging behaviour was found in summer $(\mathrm{p}=$ 0.002). A nocturnal pattern was revealed in the autumn $(\mathrm{p}=0.02)$. Nocturnal patterns in foraging activity were also found for Stn 4 in spring ( $\mathrm{p}=$ $0.011)$ and summer $(p=0.012)$. Additionally, tendencies for nocturnal patterns could be shown in winter $(p=0.079)$. Foraging behaviour at Stns 1 and 5 did not show any diel patterns.
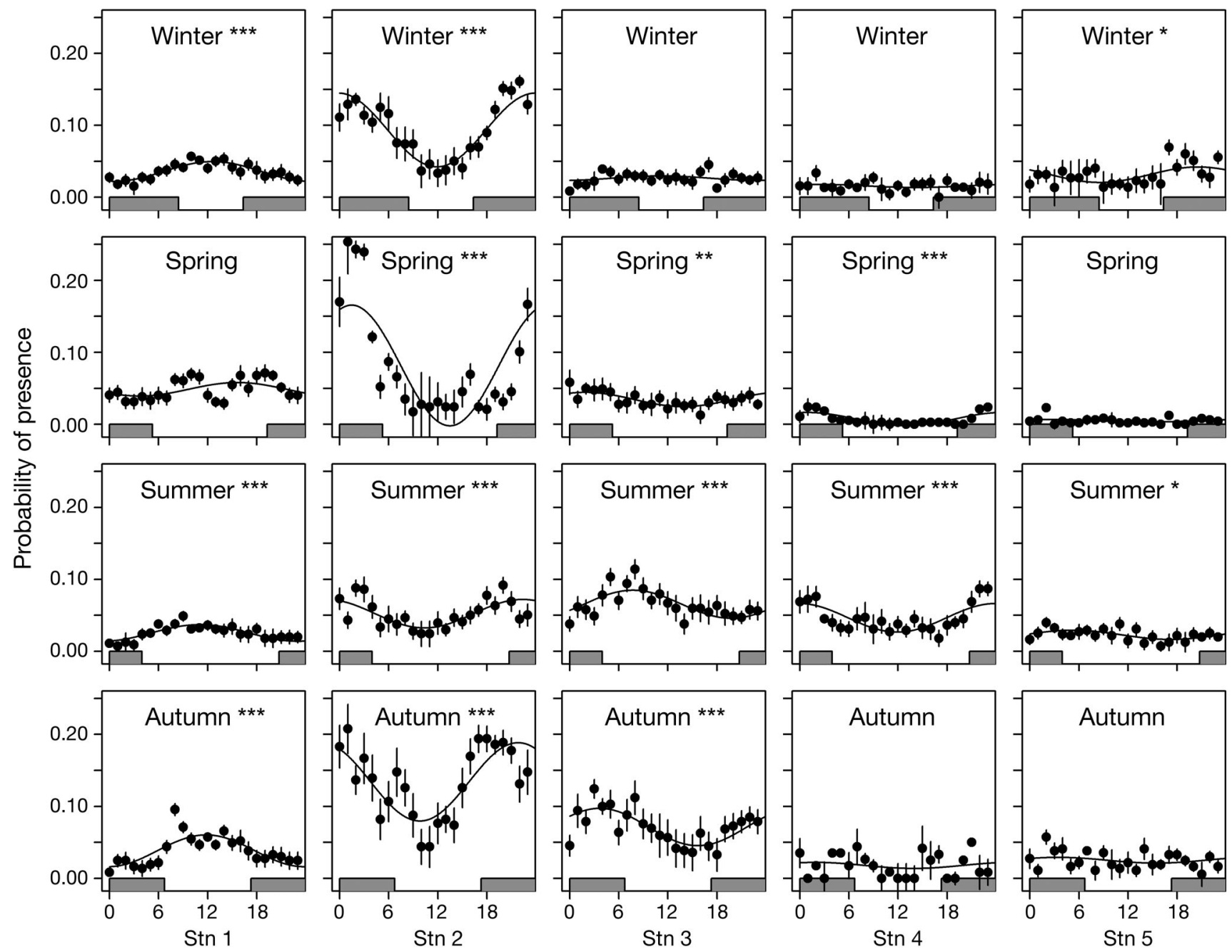

Time of day (h)

Fig. 6. Cosinor analysis of presence for all stations (left to right) separated into seasons (top to bottom). Significant diel patterns are marked: ${ }^{*} p<0.05,{ }^{* *} p<0.01,{ }^{* * *} p<0.001$. Hourly means \pm SEM are shown $(\bullet)$. Black lines show cosine fits. Grey bars at the bottom mark the mean nighttime length during the specific season for the specific station 

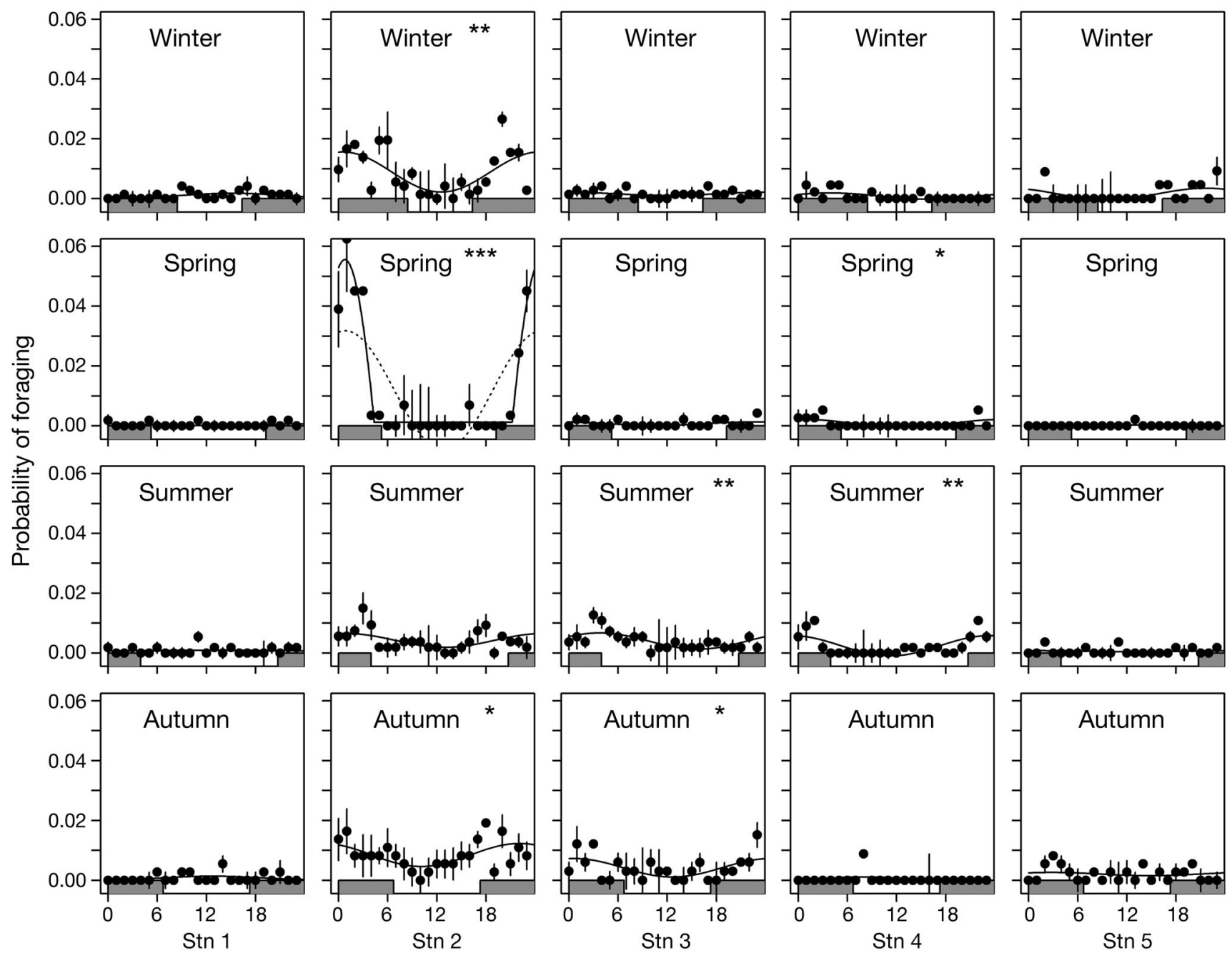

Time of day (h)

Fig. 7. Cosinor analysis of detections with foraging sequences for all stations (left to right) separated by seasons (top to bottom). Significant diel patterns are marked: ${ }^{*} \mathrm{p}<0.05,{ }^{* *} \mathrm{p}<0.01,{ }^{* * *} \mathrm{p}<0.001$. Hourly means \pm SEM are shown $(\bullet)$. Grey bars at the bottom mark the mean nighttime length during the specific season for the specific station. Black lines represent the calculated best fitting cosinus function describing the diel variations. Dashed line shown for Stn 2 in spring represents the cosine fit, which did not seem sinus-shaped; therefore, the data were fitted alternatively by a baseline-cosine fit (black line)

\section{DISCUSSION}

\section{Seasonal and diel vocalization patterns}

Cetacean species are well known for their recurring migrations and movement patterns, as well as for rhythms in foraging behaviour (Heithaus \& Dill 2002, Stern 2002). Patterns in detections and foraging behaviour can also depend on season, time of day, lunar cycle and tide (Wang et al. 2015b). Many of the seasonal and diel movements are believed to be prey-driven (e.g. Bräger 1993, Benoit-Bird et al. 2001, 2004, Benoit-Bird \& Au 2003, Ford \& Ellis 2006, Miller et al. 2010; see our 'Introduction' for additional odontocete examples). Seasonal and diel movements of harbour porpoises were studied in detail by Read \& Westgate (1997), Sveegaard et al. (2011, 2012b) and Teilmann et al. (2013). For prey fish in the Baltic Sea, the seasonal migrations of herring have been tracked by fishermen for ages (e.g. Aro 2002) and are believed to coincide with porpoise movements (e.g. Koschinski 2002, Sveegaard et al. 2012a,b, Benke et al. 2014). In the study area, harbour porpoises expand their range eastwards during summer, as can also be seen in Fig. 3, with porpoise presence concentrating increasingly in summer and autumn months from Stns 1 to 5 (i.e. west to east). 
The pattern of diel rhythms found in the western part of the Baltic Sea over a long period and large geographical scale proved to be rather complex. The results of the 5 stations from the current study show that foraging behaviour is site-specific as well as seasonally variable. Rhythms in foraging activity were found for 3 of 5 stations and were all nocturnal, i.e. peaking at midnight or at sunrise (Table 2). The seasonal variation in the feeding pattern, however, was less clear. Only Stn 2 provided a sufficient number of fp10min ( $\mathrm{n}=363$, or $9.0 \%$ of all pp10min at that station) to show a seasonal variability. In winter and spring, almost all recorded foraging took place at night, whereas in summer and autumn foraging was recorded frequently at night and in the daytime (Fig. 4). There are several possible reasons for this seasonal change in feeding behaviour, such as alterations in the availability of prey fish or changes in the energy demands of the porpoises, e.g. owing to birthing or lactation.

\section{Comparison with other studies}

A nocturnal increase in the detection of free-ranging harbour porpoise foraging sequences was described previously by Carlström (2005), Todd et al. (2009), Linnenschmidt et al. (2013), Mikkelsen et al. (2013) and Brandt et al. (2014). Distinction criteria for detecting foraging events such as ICI below $10 \mathrm{~ms}$ or mean ICI (used in Koschinski et al. 2008, Todd. et al. 2009) are too imprecise to classify foraging behaviour alone.

Using the buzz rather than the sudden decrease in ICI as a criterion could lead to different results, as shown in Table 1. The relative occurrence of buzzes was higher than the relative occurrence of verified foraging sequences, depending on the station (Table 1). A high variation between stations in the relative occurrence of fp10min in all analysed buzz-positive 10 min intervals was found. At Stn 1,56.8\% of the buzz-positive $10 \mathrm{~min}$ periods were categorized as fp10min, whereas $73.3 \%$ could be ascertained at Stn 3. Additionally, using only a 'buzz' as a criterion for foraging increases the uncertainty of the results obtained, as it is unknown whether a sequence is emitted for echolocation or for communication. Clausen et al. (2011) identified several distinct click sequences serving different communication tasks. Four of these, the so-called 'aggressive behaviour', 'contact calls', 'approach' and 'grooming', show a sudden decrease in ICI comparable to foraging sequences with maximum click rates of between 400 and $1100 \mathrm{~s}^{-1}$. These click rates correspond to minimum ICI of 0.9 to 2.5 $\mathrm{ms}$, which was also reported for foraging sequences (1.5 ms; Verfuß et al. 2009). Accordingly, all 4 communication patterns have a high similarity to the terminal phase of the approach in foraging sequences. The maximum ICI for aggressive behaviour click sequences does not exceed $5 \mathrm{~ms}$. Therefore, aggressive behaviour sequences can be separated from foraging sequences. Nevertheless, a distinction between incomplete foraging sequences and the 3 other mentioned communication behaviours is not possible. The classification of the sudden decrease in the ICI during a foraging event as the most stereotypical part enables researchers to develop algorithms for prey catch to filter data automatically. However, stricter criteria such as ICI around 1.5 to $2.5 \mathrm{~ms}$ are unlikely to lead to a more accurate classification with T-PODs, due to the scan limit of the instrument preventing a detection of the buzz itself. Additionally, a decrease in the sound pressure level of individual clicks by about $12 \mathrm{~dB}$ close to the catch of the fish decreases the probability of detection by a T-POD (Verfuß et al. 2009).

An increased detection of foraging sequences at one location or at a distinct time could be caused by a change in either behaviour or distribution of the harbour porpoises. Changes in occurrence inevitably alter the likelihood of recording foraging sequences, without necessarily a change in foraging behaviour. A comparison of the proportion of fp10min within the pp10min periods (Fig. 4) can thus determine whether

Table 2. Diel patterns found by the Lomb-Scargle periodograms (LSP) and of significant peaks found by cosinor analysis for all stations. pp10min: porpoise-positive 10 min period; fp10min: foraging-positive 10 min period; (-) no diel pattern

\begin{tabular}{|c|c|c|c|c|c|c|c|c|c|c|}
\hline \multirow[t]{2}{*}{ Stn } & \multirow[t]{2}{*}{ LSP } & \multicolumn{4}{|c|}{ pp10min cosinor } & \multirow[t]{2}{*}{ LSP } & \multicolumn{4}{|c|}{ - fp10min cosinor } \\
\hline & & Spring & Summer & Autumn & Winter & & Spring & Summer & Autumn & Winter \\
\hline 1 & Yes & - & Midday & Midday & Midday & No & - & - & - & - \\
\hline 2 & Yes & Midnight & Midnight & Midnight & Midnight & Yes & Midnight & - & Midnight & Midnight \\
\hline 3 & Yes & Night & After sunrise & Before sunrise & - & No & - & Sunrise & Midnight & - \\
\hline 4 & Yes & Midnight & Midnight & - & - & Yes & Sunrise & Midnight & - & - \\
\hline 5 & No & - & Sunrise & - & Midnight & No & - & - & - & - \\
\hline
\end{tabular}


a rise in fp10min is caused by a change in density or behaviour. Although these findings agree with most studies in terms of detecting increases in foraging activity predominantly at night (Carlström 2005, Todd et al. 2009, Linnenschmidt et al. 2013, Mikkelsen et al. 2013, Brandt et al. 2014), they also indicate that the feeding ecology of porpoises is more complicated. A consistent pattern of foraging activity throughout the entire year was not found for any of the analysed stations. Acoustic detections and the number of foraging sequences varied seasonally and among stations, indicating that porpoises may adapt their behaviour on different spatial and temporal scales. They either change from foraging to non-foraging behaviour, or they use different foraging strategies, possibly adapted to the availability of and preference for certain prey species throughout the year. A change in harbour porpoise foraging strategy may be caused, for example, by switching from benthic to pelagic prey or vice versa.

\section{Porpoise foraging and prey behaviour in the Baltic Sea}

Harbour porpoises show different behaviour patterns when foraging for benthic prey items such as some gobies (Gobiidae) and sandeels (Ammodytidae), which hide in the sediment in the daytime during autumn and winter (Ehrenberg \& Ejdung 2008). In these seasons, gobies occur in deeper waters with softer bottoms and increase their foraging behaviour in the water column during night, which is regarded as an anti-predator mechanism (Grabowska \& Grabowski 2005, Ehrenberg \& Ejdung 2008). While the harbour porpoise is searching for hidden prey in the sediment, it is vertically 'standing on its head' above the sediment, with the echolocation beam directed towards the seafloor. This foraging technique has been called bottom-grubbing (Desportes et al. 2000) and is unlikely to be recorded as direct path clicks on T-PODs, especially at deeper stations, where the click detector is moored at a considerable distance from the seafloor. As the T-POD is always hanging with the hydrophone directed upwards, the tube holding the electronics and batteries causes an acoustically 'blind spot' beneath it. Only isolated buzzes might be reflected from the bottom during grubbing, when the harbour porpoise suddenly changes orientation while chasing escaping prey and faces the T-POD during the fish-catch (Koschinski et al. 2008). Such events, however, are more likely to be recorded by T-PODs moored close to the bottom (i.e. at shallow positions such as Stns 1 and 5). All 3 stations in this study with nocturnal patterns in foraging activity were in waters deeper than $20 \mathrm{~m}$, which may be related to preying on pelagic fish species. At the deeper stations, the prevalence of vertical migration of fish species may be more pronounced compared to shallow areas. The foraging sequences analysed in this study thus may have originated primarily from foraging on pelagic fish at the deeper stations. Based on the data, it is not possible to discriminate between a change in foraging effort and an alteration in foraging technique.

\section{Ecology of porpoise prey species}

In the western Baltic Sea, the prey of harbour porpoises consists of several fish species, mainly herring, cod and gobies (Lick 1991, Sveegaard et al. 2012a). Some of the prey species are predominantly pelagic and schooling (such as herring, sprat and young cod), whereas others, such as most goby species (e.g. Gobius niger, Neogobius melanostomus, Pomatoschistus microps, P. minutus, P. pictus) as well as sandeels (e.g. Ammodytes marinus, A. tobianus, Hyperoplus lanceolatus) and other species (e.g. Zoarces viviparus), have a primarily benthic lifestyle. Many fish species in the Baltic Sea follow diel behaviour patterns (e.g. Hansson et al. 1990, Cardinale et al. 2003, Axenrot et al. 2004, Grabowska \& Grabowski 2005, Bernreuther 2007, Espeland et al. 2010, Nielsen et al. 2013). Predatory fish follow their prey while trying to avoid being eaten at the same time. This can lead to a vertical movement within the water column on a diel basis with mid-water or near-surface distribution at night and near-bottom distribution during daylight hours. In the Baltic Sea, as in other seas, typical fish prey such as planktonic crustaceans (e.g. calanoid copepods), mysids and ichthyoplankton perform vertical movements on a diel basis (Donner \& Lindström 1980, Rudstam et al. 1989, Kotta \& Kotta 2001, Hensler \& Jude 2007, Barz \& Hirche 2009, Ogonowski et al. 2013). This behaviour also occurs in comparatively shallow waters and is triggered by changes in light intensity to avoid predation. Following its prey, diel vertical movement of porpoise prey species has been found in young cod (Nilsson et al. 2003, Anderson et al. 2007, Espeland et al. 2010, Nielsen et al. 2013) as well as in herring and sprat (Cardinale et al. 2003, Axenrot et al. 2004, Barz \& Hirche 2009, Didrikas \& Hansson 2009). At night, predator avoidance mechanisms in herring 
are relaxed, and herring aggregate less in schools with decreased individual swim speed (Cardinale et al. 2003, Didrikas \& Hansson 2009). Therefore, it may be energetically advantageous to capture herring at night for a hunter that does not depend on light (Perry \& Neilson 1988, Espeland et al. 2010). Altogether, this prey behaviour may provide the reason for the increased nocturnal foraging activity that was verified for 3 stations. A significant diurnal rhythm in porpoise presence was found at Stn 1 in summer, autumn and winter, but no diel rhythm in foraging behaviour was detected, suggesting that this area is either of importance to harbour porpoises for reasons not primarily related to foraging or that benthic foraging sequences could not be detected by the T-POD. The shallow water depth of $8 \mathrm{~m}$ and the grainy sediment at this station may also allow harbour porpoises to prey visually on gobies hidden in the sand or among rocks. It may be energetically more advantageous to perform bottom-grubbing in shallower waters to avoid frequent deep and long dives, as proposed by Brandt et al. (2014). Gobies and sandeels have a low acoustic reflectivity and presumably are more difficult to detect with echolocation clicks than pelagic fish with a swim bladder, since swim bladders account for 90 to $95 \%$ of the reflected acoustic energy in fish (McCartney \& Stubbs 1971, Foote 1980, Didrikas \& Hansson 2004). The effects of sound absorption by scattering bubble clouds could also decrease the echolocation ability of harbour porpoises in shallow waters (Clay \& Medwin 1977, Leighton 1994). Therefore, visual perception might become more important when foraging for gobies.

\section{CONCLUSIONS}

The harbour porpoise in the Baltic Sea is an apex predator with a rather complex temporal and spatial distribution pattern while adapting its foraging strategy to prey behaviour. Differences in the occurrence of foraging sequences between stations, seasons and times of day lead to the conclusion that the diel pattern a porpoise displays in a certain area depends on its habitat characteristics and its temporal changes in food availability. Therefore, the development of adaptive foraging strategies may be required for an animal with a high permanent energy demand. The emerging diel pattern includes geographical and vertical movements throughout the day, probably to forage more effectively in shallower waters at daytime and in deeper waters at night.
Acknowledgements. The long-term passive acoustic monitoring projects were funded by the German Federal Ministry for the Environment, Nature Conservation and Nuclear Safety (BMU) through the Project Management Jülich (PTJ) and through the German Federal Agency for Nature Conservation (BfN). We are grateful to our colleague C. G. Honnef for help during data collection, T. Moritz and J. Wood for reviewing an earlier draft of the manuscript, and U. Siebert and H. Mehlhorn for advising T.S. during his studies. The views expressed in this paper are those of the authors and do not necessarily reflect the position of the International Seabed Authority.

\section{LITERATURE CITED}

Akamatsu T, Teilmann J, Miller LA, Tougaard J and others (2007) Comparison of echolocation behaviour between coastal and riverine porpoises. Deep-Sea Res II 54: 290-297

Anderson JL, Laurel BJ, Brown JA (2007) Diel changes in behaviour and habitat use by age-0 Atlantic cod (Gadus morhua L.) in the laboratory and field. J Exp Mar Biol Ecol 351:267-275

Aro E (2002) Fish migration studies in the Baltic Sea - a historical review. ICES Mar Sci Symp 215:361-370

Au WWL (1993) The sonar of dolphins. Springer, New York, NY

Au WWL, Giorli G, Chen J, Copeland A and others (2013) Nighttime foraging by deep diving echolocating odontocetes off the Hawaiian islands of Kauai and Ni'ihau as determined by passive acoustic monitors. J Acoust Soc Am 133:3119-3127

Au WWL, Giorli G, Chen J, Copeland A, Lammers MO, Richlen M (2014) Presence and seasonal variation of deep diving foraging odontocetes around Kauai, Hawaii using remote autonomous acoustic recorders. J Acoust Soc Am 135:521-530

Axenrot T, Didrikas T, Danielsson C, Hansson S (2004) Diel patterns in pelagic fish behaviour and distribution observed from a stationary, bottom-mounted, and upwardfacing transducer. ICES J Mar Sci 61:1100-1104

> Barz K, Hirche HJ (2009) Ecology of mysid shrimps in the Bornholm basin (central Baltic Sea). Helgol Mar Res 63: 317-326

Batschelet E (1981) Circular statistics in biology, Vol 371. Academic Press, London

> Benke H, Bräger S, Dähne M, Gallus A and others (2014) Baltic Sea harbour porpoise populations: status and conservation needs derived from recent survey results. Mar Ecol Prog Ser 495:275-290

Benoit-Bird KJ, Au WWL (2003) Prey dynamics affect foraging by a pelagic predator (Stenella longirostris) over a range of spatial and temporal scales. Behav Ecol Sociobiol 53:364-373

Benoit-Bird KJ, Au WWL, Brainard RE, Lammers MO (2001) Diel horizontal migration of the Hawaiian mesopelagic boundary community observed acoustically. Mar Ecol Prog Ser 217:1-14

Benoit-Bird KJ, Würsig B, McFadden CJ (2004) Dusky dolphin (Lagenorhynchus obscurus) foraging in two different habitats: active acoustic detection of dolphins and their prey. Mar Mamm Sci 20:215-231

Bernreuther M (2007) Investigations on the feeding ecology of Baltic Sea herring (Clupea harengus L.) and sprat 
(Sprattus sprattus L.). PhD dissertation, University of Hamburg

- Bräger S (1993) Diurnal and seasonal behaviour patterns of bottlenose dolphins (Tursiops truncatus). Mar Mamm Sci 9:434-438

Brandt MJ, Hansen S, Diederichs A, Nehls G (2014) Do manmade structures and water depth affect the diel rhythms in click recordings of harbor porpoises (Phocoena phocoena)? Mar Mamm Sci 30:1109-1121

> Campos MC, Costa JL, Quintella BR, Costa MJ, Almeida PR (2008) Activity and movement patterns of the Lusitanian toadfish inferred from pressure-sensitive data-loggers in the Mira estuary (Portugal). Fish Manag Ecol 15:449-458

Cardinale M, Casini M, Arrhenius F, Håkansson N (2003) Diel spatial distribution and feeding activity of herring (Clupea harengus) and sprat (Sprattus sprattus) in the Baltic Sea. Aquat Living Resour 16:283-292

> Carlström J (2005) Diel variation in echolocation behavior of wild harbor porpoises. Mar Mamm Sci 21:1-12

> Christensen JT, Richardson K (2008) Stable isotope evidence of long-term changes in the North Sea food web structure. Mar Ecol Prog Ser 368:1-8

> Clausen KT, Beedholm K, DeRuiter S, Madsen PT, Wahlberg M (2011) Click communication in harbour porpoises Phocoena phocoena. Bioacoustics 20:1-28

Clay CS, Medwin H (1977) Acoustical oceanography: principles and applications, Vol 4. Wiley, New York, NY

Dähne M, Gilles A, Lucke K, Peschko V and others (2013) Effects of pile-driving on harbour porpoises (Phocoena phocoena) at the first offshore wind farm in Germany. Environ Res Lett 8: 25002

> Dede A, Öztürk AA, Akamatsu T, Tonay AM, Öztürk B (2014) Long-term passive acoustic monitoring revealed seasonal and diel patterns of cetacean presence in the Istanbul Strait. J Mar Biol Assoc UK 94:1195-1202

> DeRuiter SL, Bahr A, Blanchet MA, Hansen SF and others (2009) Acoustic behaviour of echolocating porpoises during prey capture. J Exp Biol 212:3100-3107

Didrikas T, Hansson S (2004) In situ target strength of the Baltic Sea herring and sprat. ICES J Mar Sci 61:378-382

> Didrikas T, Hansson S (2009) Effects of light intensity on activity and pelagic dispersion of fish: studies with a seabed-mounted echosounder. ICES J Mar Sci 66: 388-395

> Dong L, Wang D, Wang K, Li S and others (2015) Yangtze finless porpoises along the main channel of Poyang Lake, China: implications for conservation. Mar Mamm Sci 31: 612-628

Donner KO, Lindström M (1980) Sensitivity to light and diel activity of Pontoporeia affinis (Crustacea, Amphipoda). Ann Zool Fenn 17:203-202

Ehrenberg SZ, Ejdung G (2008) Daily activity pattern of the sand goby, Pomatoschistus minutus (Pisces), at low light intensity. Hydrobiologia 603:129-137

Espeland SH, Thoresen AG, Olsen EM, Stige LC, Knutsen H, Gjøsæter J, Stenseth NC (2010) Diel vertical migration patterns in juvenile cod from the Skagerrak coast. Mar Ecol Prog Ser 405:29-37

Foote KG (1980) Importance of the swimbladder in acoustic scattering by fish: a comparison of gadoid and mackerel target strengths. J Acoust Soc Am 67:2084

Ford JKB, Ellis GM (2006) Selective foraging by fish-eating killer whales Orcinus orca in British Columbia. Mar Ecol Prog Ser 316:185-199

Frohlich M, Berger A, Kramer-Schadt S, Heckmann I, Mar- tins Q (2012) Complementing GPS cluster analysis with activity data for studies of leopard (Panthera pardus) diet. S Afr J Wildl Res 42:104-110

Galatius A, Kinze CC, Teilmann J (2012) Population structure of harbour porpoises in the Baltic region: evidence of separation based on geometric morphometric comparisons. J Mar Biol Assoc UK 92:1669-1676

Gallus A, Dähne M, Verfuß UK, Bräger S, Adler S, Siebert U, Benke H (2012) Use of static passive acoustic monitoring to assess the status of the 'Critically Endangered' Baltic harbour porpoise in German waters. Endang Species Res $18: 265-278$

Goold JC (2000) A diel pattern in vocal activity of shortbeaked common dolphins, Delphinus delphis. Mar Mamm Sci 16:240-244

- Grabowska J, Grabowski M (2005) Diel-feeding activity in early summer of racer goby Neogobius gymnotrachelus (Gobidae): a new invader in the Baltic basin. J Appl Ichthyol 21:282-286

Hammond PS, Bearzi G, Bjørge A, Forney K and others (2008) Phocoena phocoena (Baltic Sea subpopulation). IUCN Red List of Threatened Species. Available at www.iucnredlist.org (accessed on 18 November 2015)

Hansson S, Larsson U, Johansson S (1990) Selective predation by herring and mysids, and zooplankton community structure in a Baltic Sea coastal area. J Plankton Res 12: 1099-1116

Heithaus MR, Dill LM (2002) Feeding strategies and tactics. In: Perrin WF, Würsig B, Thewissen JGM (eds) Encyclopedia of marine mammals. Academic Press, San Diego, CA, p 412-422

Hensler SR, Jude DJ (2007) Diel vertical migration of round goby larvae in the Great Lakes. J Gt Lakes Res 33: 295-302

Hodge LEW, Bell JT, Kumar A, Read AJ (2013) The influence of habitat and time of day on the occurrence of odontocete vocalizations in Onslow Bay, North Carolina. Mar Mamm Sci 29:E411-E427

Koopman HN (1998) Topographical distribution of the blubber of harbor porpoises (Phocoena phocoena). J Mammal 79:260-270

- Koschinski S (2002) Current knowledge on harbour porpoises (Phocoena phocoena) in the Baltic Sea. Ophelia 55:167-197

Koschinski S, Diederichs A, Amundin M (2008) Click train patterns of free-ranging harbour porpoises acquired using T-PODs may be useful as indicators of their behaviour. J Cetacean Res Manag 10:147-155

Kotta I, Kotta J (2001) Vertical migrations of mysids in the Gulf of Riga. Proc Estonian Acad Sci Biol Ecol 50: 248-255

Kyhn LA, Tougaard J, Teilmann J, Wahlberg M, Jørgensen PB, Bech N (2008) Harbour porpoise (Phocoena phocoena) static acoustic monitoring: laboratory detection thresholds of T-PODs are reflected in field sensitivity. J Mar Biol Assoc UK 88:1085-1091

Leeney RH, Carslake D, Elwen SH (2011) Using static acoustic monitoring to describe echolocation behaviour of Heaviside's dolphins (Cephalorhynchus heavisidii) in Namibia. Aquat Mamm 37:151-160

Leighton TG (1994) The acoustic bubble. Academic Press, London

Lick RR (1991) Parasites from the digestive tract and food analysis of harbour porpoise Phocoena phocoena from German coastal waters. Eur Res Cetaceans 5:65-68 
Lin X, Zhang D (1999) Inference in generalized additive mixed models by using smoothing splines. J Roy Stat Soc B 61:381-400

Lin TH, Yu HY, Chen CF, Chou LS (2015) Passive acoustic monitoring of the temporal variability of odontocete tonal sounds from a long-term marine observatory. PLoS ONE 10:e0123943

> Linnenschmidt M, Teilmann J, Akamatsu T, Dietz R, Miller LA (2013) Biosonar, dive, and foraging activity of satellite tracked harbor porpoises (Phocoena phocoena). Mar Mamm Sci 29:E77-E97

> Lockyer C (2007) All creatures great and smaller: a study in cetacean life history energetics. J Mar Biol Assoc UK 87: 1035-1045

> Lomb NR (1976) Least-squares frequency analysis of unequally spaced data. Astrophys Space Sci 39:447-462

> López-Duarte PC, Tankersley RA (2007) Circatidal swimming behaviors of fiddler crab Uca pugilator larvae from different tidal regimes. Mar Ecol Prog Ser 343:207-220

> López-Duarte PC, Christy JH, Tankersley RA (2011) A behavioral mechanism for dispersal in fiddler crab larvae (genus Uca) varies with adult habitat, not phylogeny. Limnol Oceanogr 56:1879-1892

Madsen PT, Surlykke A (2013) Functional convergence in bat and toothed whale biosonars. Physiology 28: 276-283

> Mat AM, Massabuau JC, Ciret P, Tran D (2012) Evidence for a plastic dual circadian rhythm in the oyster Crassostrea gigas. Chronobiol Int 29:857-867

McCartney BS, Stubbs AR (1971) Measurements of the acoustic target strengths of fish in dorsal aspect, including swimbladder resonance. J Sound Vib 15:397-420

Mikkelsen L, Mouritsen KN, Dahl K, Teilmann J, Tougaard J (2013) Re-established stony reef attracts harbour porpoises Phocoena phocoena. Mar Ecol Prog Ser 481: 239-248

Miller LA, Pristed J, Moshl B, Surlykke A (1995) The clicksounds of narwhals (Monodon monoceros) in Inglefield Bay, northwest Greenland. Mar Mamm Sci 11:491-502

Miller LJ, Solangi M, Kuczaj SA (2010) Seasonal and diurnal patterns of behaviour exhibited by Atlantic bottlenose dolphins (Tursiops truncatus) in the Mississippi Sound. Ethology 116:1127-1137

Nielsen JR, Lundgren B, Kristensen K, Bastardie F (2013) Localisation of nursery areas based on comparative analyses of the horizontal and vertical distribution patterns of juvenile Baltic cod (Gadus morhua). PLoS ONE 8:e70668

Nilsson LAF, Thygesen UH, Lundgren B, Nielsen BF, Nielsen JR, Beyer JE (2003) Vertical migration and dispersion of sprat (Sprattus sprattus) and herring (Clupea harengus) schools at dusk in the Baltic Sea. Aquat Living Resour 16:317-324

Nuuttila H, Meier R, Evans P, Turner JR, Bennell JD, Hidding JG (2013) Identifying foraging behaviour of wild bottlenose dolphins (Tursiops truncatus) and harbour porpoises (Phocoena phocoena) with static acoustic dataloggers. Aquat Mamm 39:147-161

Ogonowski M, Hansson S, Duberg J (2013) Status and vertical size-distributions of a pelagic mysid community in the northern Baltic proper. Boreal Environ Res 18:1-18

Perry RI, Neilson JD (1988) Vertical distributions and trophic interactions of age- 0 Atlantic cod and haddock in mixed and stratified waters of Georges Bank. Mar Ecol Prog Ser 49:199-214
Press WH, Teukolsky SA, Vetterling WT, Flannery BP (1994) Numerical recipes in $\mathrm{C}$ : the art of scientific computing, 2nd edn. Cambridge University Press, Cambridge

R Core Team (2013) R: a language and environment for statistical computing. R Foundation for Statistical Computing, Vienna. www.r-project.org

> Read AJ, Westgate AJ (1997) Monitoring the movements of harbour porpoises (Phocoena phocoena) with satellite telemetry. Mar Biol 130:315-322

> Risch D, Clark CW, Dugan PJ, Popescu M, Siebert U, Van Parijs SM (2013) Minke whale acoustic behavior and multi-year seasonal and diel vocalization patterns in Massachusetts Bay, USA. Mar Ecol Prog Ser 489: 279-295

> Rudstam LG, Danielsson K, Hansson S, Johansson S (1989) Diel vertical migration and feeding patterns of mysismixta (Crustacea, Mysidacea) in the Baltic Sea. Mar Biol 101:43-52

> Ruf T (1996) The baseline cosinus function: a periodic regression model for biological rhythms. Biol Rhythm Res 27:153-165

Ruf T (1999) The Lomb-Scargle periodogram in biological rhythm research: analysis of incomplete and unequally spaced time-series. Biol Rhythm Res 30:178-201

Ruf T (2013) Lomb-Scargle periodogram. R package version 1.0. http://cran.r-project.org/web/packages/lomb/

Santos MB, Pierce GJ, Learmonth JA, Reid RJ, Ross HM, Patterson IAP (2004) Variability in the diet of harbor porpoises (Phocoena phocoena) in Scottish waters 19922003. Mar Mamm Sci 20:1-27

Sasaki-Yamamoto Y, Akamatsu T, Ura T, Sugimatsu H and others (2013) Diel changes in the movement patterns of Ganges river dolphins monitored using stationed stereo acoustic data loggers. Mar Mamm Sci 29:589-605

Scargle JD (1982) Studies in astronomical time series analysis. II. Statistical aspects of spectral analysis of unevenly spaced data. Astrophys J 263:835-853

Soldevilla MS, Wiggins SM, Hildebrand JA (2010a) Spatiotemporal comparison of Pacific white-sided dolphin echolocation click types. Aquat Biol 9:49-62

Soldevilla MS, Wiggins SM, Hildebrand JA (2010b) Spatial and temporal patterns of Risso's dolphin echolocation in the Southern California Bight. J Acoust Soc Am 127: $124-132$

Stern SJ (2002) Migration and movement patterns. In: Perrin MR, Würsig B, Thewissen JGM (eds) Encyclopedia of marine mammals Academic Press, San Diego, CA, p 726-730

Sveegaard S, Teilmann J, Tougaard J, Dietz R, Mouritsen KN, Desportes G, Siebert U (2011) High density areas for harbor porpoises (Phocoena phocoena) identified by satellite tracking. Mar Mamm Sci 27:230-246

> Sveegaard S, Andreasen H, Mouritsen KN, Jeppesen JP, Teilmann J, Kinze CC (2012a) Correlation between the seasonal distribution of harbour porpoises and their prey in the Sound, Baltic Sea. Mar Biol 159:1029-1037

Sveegaard S, Nabe-Nielsen J, Stæhr KJ, Jensen TF, Mouritsen KN, Teilmann J (2012b) Spatial interactions between marine predators and their prey: herring abundance as a driver for the distributions of mackerel and harbour porpoise. Mar Ecol Prog Ser 468:245-253

Teilmann J, Christiansen CT, Kjellerup S, Dietz R, Nachman G (2013) Geographic, seasonal, and diurnal surface behavior of harbor porpoises. Mar Mamm Sci 29: E60-E76 
Todd VLG, Pearse WD, Tregenza NC, Lepper PA, Todd IB (2009) Diel echolocation activity of harbour porpoises (Phocoena phocoena) around North Sea offshore gas installations. ICES J Mar Sci 66:734-745

Verfuß UK, Miller LA, Schnitzler HU (2005) Spatial orientation in echolocating harbour porpoises (Phocoena phocoena). J Exp Biol 208:3385-3394

Verfuß UK, Honnef CG, Meding A, Dähne M, Mundry R, Benke H (2007) Geographical and seasonal variation of harbour porpoise (Phocoena phocoena) presence in the German Baltic Sea revealed by passive acoustic monitoring. J Mar Biol Assoc UK 87:165-176

Verfuß UK, Honnef CG, Medling A, Dähne M, Adler S, Kilian A, Benke H (2008) The history of the German Baltic Sea harbour porpoise acoustic monitoring at the German Oceanographic Museum. In: Wollny-Goerke K, Eskildsen K (eds) Marine mammals and seabirds in front of offshore wind energy. Teubner, Wiesbaden, p 41-56

Verfuß UK, Miller LA, Pilz PKD, Schnitzler HU (2009) Echolocation by two foraging harbour porpoises (Phocoena phocoena). J Exp Biol 212:823-834

Verfuß U, Adler S, Brandecker A, Dähne M, Diederichs A, Gallus A, Herrmann A (2010) AMPOD applications and analysis methods for the deployment of T-PODs in environmental impact studies for wind farms: comparability and development of standard methods. Deutsches Meeresmuseum, Stralsund

> Verfuß UK, Dähne M, Gallus A, Jabbusch M, Benke H (2013) Determining the detection thresholds for harbor porpoise clicks of autonomous data loggers, the Timing Porpoise Detectors. J Acoust Soc Am 134: 2462-2468

> Viquerat S, Herr H, Gilles A, Peschko V, Siebert U, Sveegaard S, Teilmann J (2014) Abundance of harbour por-

Editorial responsibility: Peter Corkeron, Woods Hole, Massachusetts, USA poises (Phocoena phocoena) in the western Baltic, Belt Seas and Kattegat. Mar Biol 161:745-754

> Wang Z, Akamatsu T, Wang KX, Wang D (2014) The diel rhythms of biosonar behavior in the Yangtze finless porpoise (Neophocaena asiaeorientalis asiaeorientalis) in the port of the Yangtze River: the correlation between prey availability and boat traffic. PLoS ONE 9:e7907

- Wang Z, Akamatsu T, Mei ZG, Dong LJ, Imaizumi T, Wang KX, Wang D (2015a) Frequent and prolonged nocturnal occupation of port areas by Yangtze finless porpoises (Neophocaena asiaeorientalis): forced choice for feeding? Integr Zool 10:122-132

Wang ZT, Nachtigall PE, Akamatsu T, Wang KX and others (2015b) Passive acoustic monitoring the diel, lunar, seasonal and tidal patterns in the biosonar activity of the Indo-Pacific humpback dolphins (Sousa chinensis) in the Pearl River estuary, China. PLoS ONE 10:e0141807

> Wiemann A, Andersen LW, Berggren P, Siebert U and others (2010) Mitochondrial control region and microsatellite analyses on harbour porpoise (Phocoena phocoena) unravel population differentiation in the Baltic Sea and adjacent waters. Conserv Genet 11:195-211

Wood SN (2006) Generalized additive models: an introduction with R. Chapman \& Hall, Boca Raton, FL

> Wood SN (2011) Fast stable restricted maximum likelihood and marginal likelihood estimation of semiparametric generalized linear models. J R Stat Soc B 73:3-36

Yamamoto Y, Akamatsu T, da Silva VMF, Kohshima S (2015) Local habitat use by botos (Amazon river dolphins, Inia geoffrensis) using passive acoustic methods. Mar Mamm Sci 32:220-240

> Zuur AF, Ieno EN, Elphick CS (2010) A protocol for data exploration to avoid common statistical problems. Methods Ecol Evol 1:3-14

Submitted: June 8, 2015; Accepted: January 22, 2016

Proofs received from author(s): March 18, 2016 